\title{
THE ESTIMATION OF SODIUM GENTISATE IN PLASMA AND URINE
}

\author{
BY \\ B. W. MEADE AND M. J. H. SMITH \\ From the Department of Chemical Pathology, King's College Hospital Medical \\ School, London
}

(RECEIVED FOR PUBLICATION DECEMBER 7, 1950)

The sodium salt of gentisic acid has been used in the treatment of rheumatic fever (Meyer and Ragan, 1948). It has been reported that the substance is as active therapeutically as sodium salicylate and has the advantage that it produces few, if any, toxic effects even in doses up to $18 \mathrm{~g}$. per day (Camelin, Accoyer, Pellerat, Lafuma, and Coirault, 1949).

The concentrations of gentisate in plasma and urine have been measured by means of the blue colour given with ferric chloride (Camelin et al., 1949) or by the determination of the optical density at $320 \mathrm{~m} \mu$ (Consden and Stanier, 1951). In our opinion neither of these methods is suitable for routine estimations; the ferric chloride reaction is too transient for accurate work, and the measurement of the optical density at $320 \mathrm{~m} \mu$ needs an ultra-violet spectrophotometer. We have therefore devised a photometric method of estimation based on the blue colour given by gentisate with the Folin-Ciocalteu phenol reagent in alkaline solution (Smith, 1950).

\section{Method}

Gentisic acid is quantitatively extracted from acidified plasma or urine by ethyl acetate and completely removed from the organic solvent by $1 \% \mathrm{w} / \mathrm{v}$ sodium bicarbonate solution at $p \mathrm{H}$ 8.5. The alkalinity of the final extraction medium is a critical factor

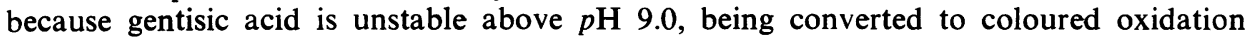
products. A stronger alkali than $1 \% \mathrm{w} / \mathrm{v}$ sodium bicarbonate solution completely extracts the gentisic acid from the ethyl acetate, but also causes decomposition of the substance.

The gentisic acid in the bicarbonate extract is estimated by means of its reaction with an aqueous solution of the Folin-Ciocalteu phenol reagent, which is readily available in most clinical laboratories. A blue colour having an absorption maximum at $660 \mathrm{~m} \mu$ develops on the addition of sodium hydroxide ; the colour intensity reaches a maximum after one minute but begins to fade after 20 minutes and is reduced to $90 \%$ of the maximum intensity after two hours (Fig. 1). The absorption density of the coloured solution was found to be proportional to the concentration of sodium gentisate up to $12 \mathrm{mg} . / 100 \mathrm{ml}$. in the plasma and diluted urine, and the method gave a recovery of $96 \%$ of added sodium gentisate from plasma or urine. A calibration curve (Fig. 2) may 


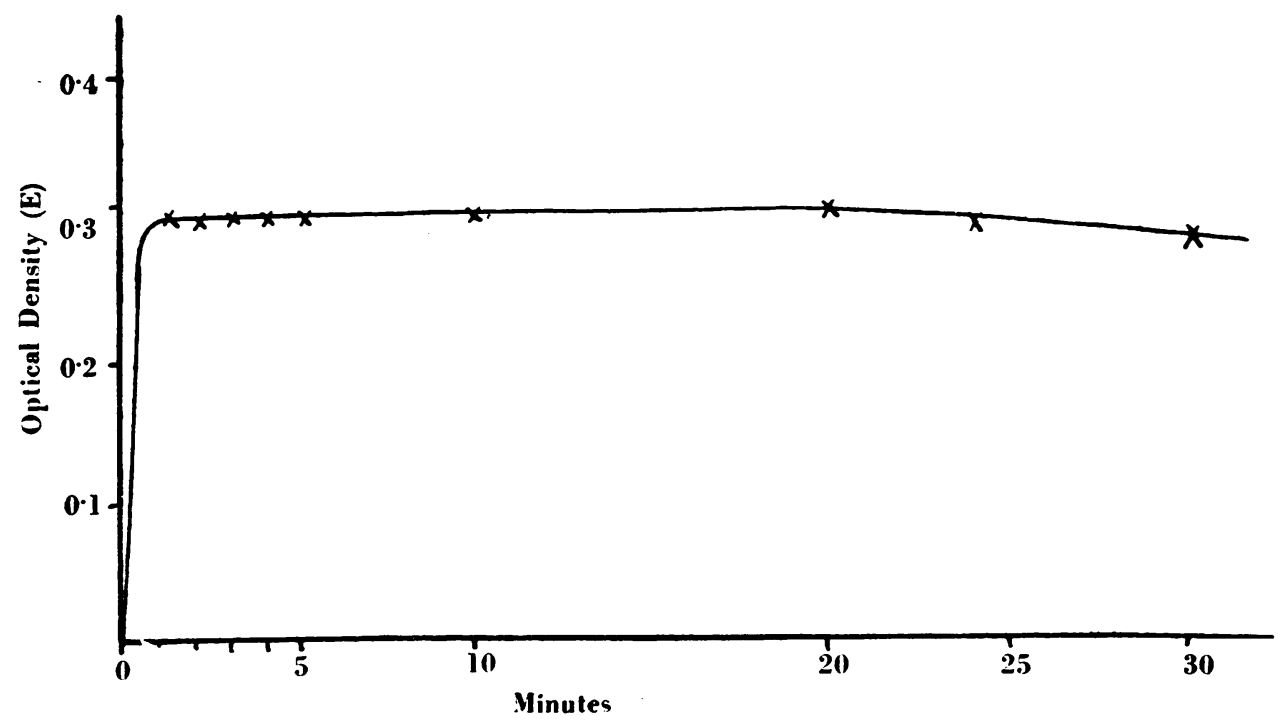

Fig. 1.-Rate of development and fading of Folin-Ciocalteu blue colour at room temperature.

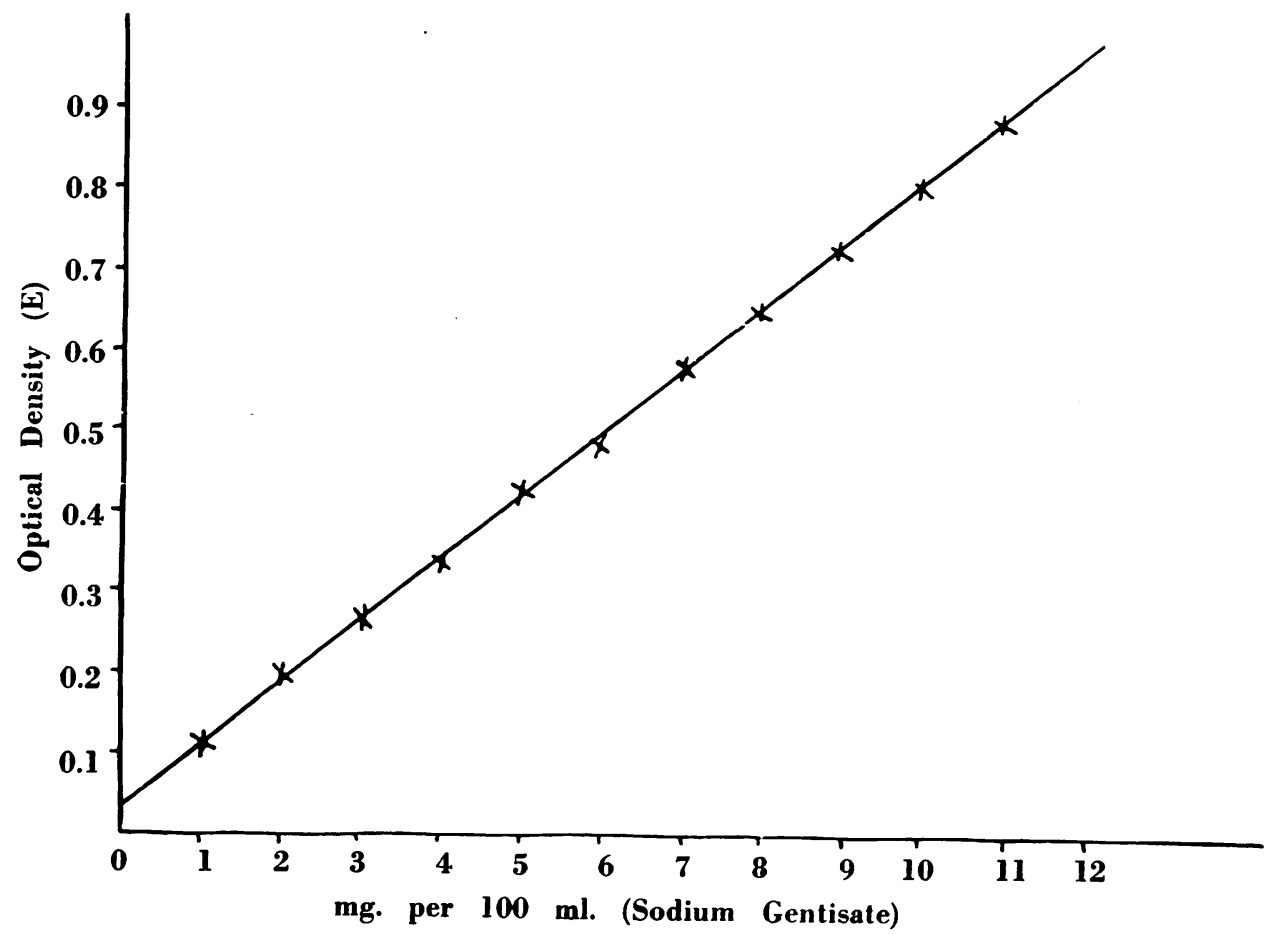

FIG. 2.-Calibration curve of sodium gentisate in distilled water, using the blue-colour given by the Folin-Ciocalteu reagent in alkaline solution. The colour intensities were ${ }_{4}$ measured in a Hilger Spekker absorptiometer using an Ilford spectrum red filter No. 608. 
be constructed from a series of solutions of sodium gentisate in distilled water, ranging in concentration from 0 to $12 \mathrm{mg}$. $/ 100 \mathrm{ml}$.

The method of estimation is as follows. To $2 \mathrm{ml}$. of plasma or $2 \mathrm{ml}$. of diluted urine (usually 1 to 100 with distilled water) $0.5 \mathrm{ml}$. of $6 \mathrm{~N} . \mathrm{HCl}$ is added, followed by $10 \mathrm{ml}$. of ethyl acetate. If concentrations greater than $12 \mathrm{mg} . / 100 \mathrm{ml}$. are to be measured then 0.5 or $1 \mathrm{ml}$. of plasma or diluted urine are made up to $2 \mathrm{ml}$. with distilled water before the addition of the $\mathrm{HCl}$ and ethyl acetate. The mixture is shaken for three minutes and centrifuged for five minutes; $5 \mathrm{ml}$. of the ethyl acetate layer are removed and added to $5 \mathrm{ml}$. of $1 \% \mathrm{w} / \mathrm{v} \mathrm{NaHCO}$ solution. The mixture is shaken and centrifuged for five minutes; $4 \mathrm{ml}$. of the bicarbonate layer are removed and $1 \mathrm{ml}$. of Folin-Ciocalteu reagent (diluted 1 to 3 with distilled water) is added and mixed. After the addition of $1 \mathrm{ml}$. of $1.5 \mathrm{~N} . \mathrm{NaOH}$ the solution is allowed to stand for five minutes and the absorption density measured against distilled water in a photo-electric absorptiometer using a $1-\mathrm{cm}$. cell and a filter transmitting maximally above $660 \mathrm{~m} \mu$. We have used a Hilger Spekker photo-electric absorptiometer and an Ilford spectrum red filter No. 608 .

Samples of plasma and urine from patients not receiving gentisate or salicylate therapy gave negligible blank values with the procedure described above.

\section{Results}

Two women, Case 1, aged 16 years (weight $45 \mathrm{~kg}$.), convalescent from a unilateral pleural effusion, and Case 2, aged 18 years (weight $58 \mathrm{~kg}$.), with an artificial pneumothorax, both confined to bed, were given $12 \mathrm{~g}$. of sodium gentisate per day. Four tablets $(0.25 \mathrm{~g}$.) were given every two hours from 6 a.m. to 8 p.m. and $16(0.25 \mathrm{~g}$. $)$ tablets were given at 10 p.m.; there was no restriction of fluid intake. Blood samples were collected by venepuncture at 9.40 a.m. each day and 24-hour urines were collected from 6 a.m. to 6 a.m. The sodium gentisate was given for seven days, and the plasma concentrations and urinary excretion for the two subjects are given in Table I. A representative sample of the tablets was analysed for its content of sodium gentisate by Smith's (1950) method, and the calculated total intake of the substance in each case was $80.64 \mathrm{~g}$.

TABLE I

Plasma Concentrations and Urinary Excretion in Two Subjects

\begin{tabular}{|c|c|c|c|c|c|c|}
\hline \multirow{3}{*}{ Date } & \multicolumn{3}{|c|}{ Case 1} & \multicolumn{3}{|c|}{ Case 2} \\
\hline & \multirow{2}{*}{$\underset{\text { (mg./100 ml.) }}{\text { Plasma }}$} & \multicolumn{2}{|c|}{ Urine } & \multirow{2}{*}{$\underset{(\mathrm{mg} . / 100 \mathrm{ml} .)}{\text { Plasma }}$} & \multicolumn{2}{|c|}{ Urine } \\
\hline & & $\begin{array}{c}\text { 24-hr. vol. } \\
\text { (ml.) }\end{array}$ & g. $/ 24 \mathrm{hr}$. & & $\begin{array}{l}\text { 24-hr. vol. } \\
\text { (mi.) }\end{array}$ & g. $/ 24 \mathrm{hr}$ \\
\hline \multirow[t]{2}{*}{$\begin{array}{cc}\text { October } & 11,1950 \\
, & 12 \\
, & 13 \\
, & 14 \\
, & 15 \\
, & 16 \\
, & 17 \\
, & 18 \\
, & 19 \\
, & 20\end{array}$} & $\begin{array}{l}0 \\
7.55 \\
5.50 \\
7.30 \\
4.80 \\
5.60 \\
4.55 \\
4.92 \\
0 \\
0\end{array}$ & $\begin{array}{l}2,140 \\
2,900 \\
2,430 \\
2,485 \\
3,580 \\
2,710 \\
2,540 \\
2,175 \\
2,540 \\
2,100\end{array}$ & $\begin{array}{c}4.708 \\
10.585 \\
7.655 \\
9.07 \\
16.29 \\
10.84 \\
6.223 \\
7.043 \\
0.508 \\
0\end{array}$ & $\begin{array}{l}0 \\
5.80 \\
3.82 \\
4.70 \\
3.30 \\
4.90 \\
6.15 \\
4.85 \\
0.65 \\
0\end{array}$ & $\begin{array}{l}2,120 \\
2,650 \\
2,820 \\
2,420 \\
2,140 \\
2,400 \\
2,400 \\
2,480 \\
1,910 \\
1,900\end{array}$ & $\begin{array}{c}4.876 \\
9.275 \\
8.320 \\
6.897 \\
12.733 \\
10.44 \\
9.852 \\
9.672 \\
0 \\
0\end{array}$ \\
\hline & \multicolumn{3}{|c|}{$\begin{array}{llrl}\text { Total excretion in } & \text { urine } & 72.93 \mathrm{~g} . \\
\text { Total dosage } & . . & . & 80.64 \mathrm{~g} \\
\% \text { recovery } & . . & . & 90.4 \%\end{array}$} & \multicolumn{2}{|c|}{$\begin{array}{llr}\text { Total excretion in } & \text { urine } \\
\text { Total dosage } & . . & . . \\
\% \text { recovery } & . . & . .\end{array}$} & $\begin{array}{l}72.07 \mathrm{~g} . \\
80.64 \mathrm{~g} \\
89.3 \%\end{array}$ \\
\hline
\end{tabular}


A single dose of 20 tablets (equivalent to $4.80 \mathrm{~g}$. of sodium gentisate) was taken by a healthy man (weight $67 \mathrm{~kg}$.), and the plasma concentrations and urinary excretion of the drug followed over a period of 24 hours (Fig. 3).

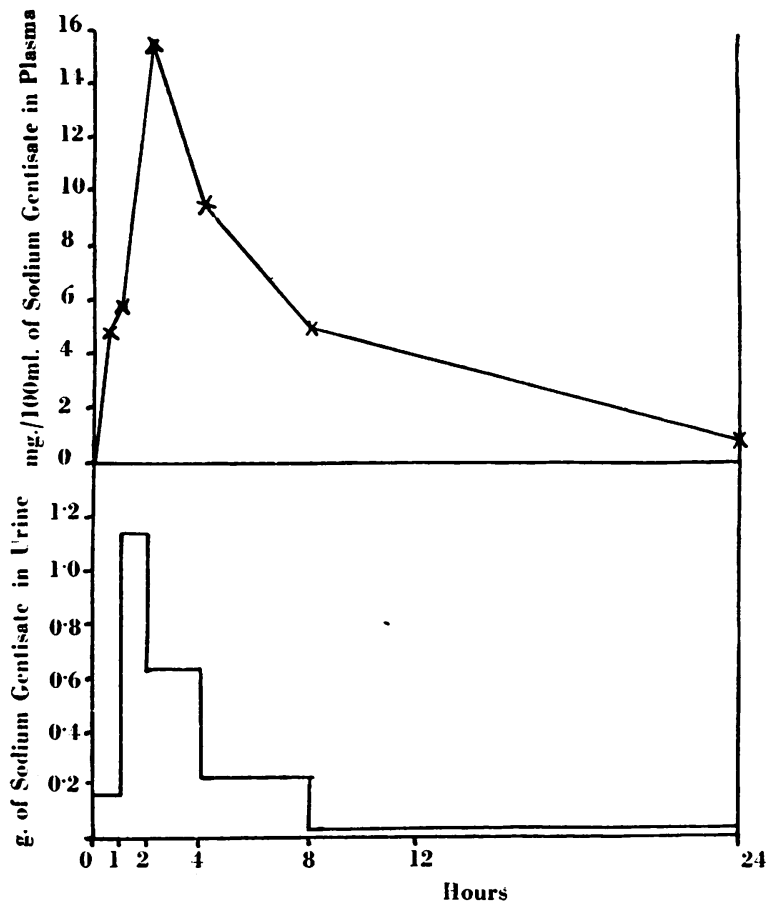

Fig. 3.-Plasma concentrations and urinary excretion over 24 hours after a single dose of $5 \mathrm{~g}$. of sodium gentisate.

\section{Discussion}

These results demonstrate that about $90 \%$ of administered gentisate was recoverable from the urine, that it was rapidly excreted, and that measurable plasma concentrations of 4 to $8 \mathrm{mg} . / 100 \mathrm{ml}$. were maintained in the two subjects receiving $12 \mathrm{~g}$. of gentisate per day. The maximum plasma concentration $(15.5 \mathrm{mg}$. $/ 100 \mathrm{ml}$. $)$ after a single dose of $5 \mathrm{~g}$. in a healthy male appeared to be reached after two hours, and $80 \%$ of the ingested dose was excreted in the urine within eight hours. These findings are not in agreement with those of Meyer and Ragan (1948), who reported that only about one-quarter of administered gentisate was recoverable from urine and that none could be detected in the blood; the method of estimation used by these authors was not given. Camelin et al. (1949) reported plasma levels of 7.5 to $10 \mathrm{mg} . / 100 \mathrm{ml}$. in patients receiving $12 \mathrm{~g}$. of gentisic acid per day in $1 \mathrm{~g}$. doses every two hours, and during the course of the present work a preliminary communication by Consden and Stanier (1951) claimed that plasma levels of between 20 and $30 \mathrm{mg} . / 100 \mathrm{ml}$. could be maintained by sufficiently high dosages and that about $90 \%$ of administered gentisate could be recovered from the urine.

It is realized that the results given above are limited in scope and that many factors such as body weight, fluid intake, urine $p \mathrm{H}$ and magnitude, and timing of doses may be of importance in determining the plasma concentration of the drug in any given patient. 


\section{Summary}

A method of estimating the concentration of sodium gentisate in plasma and urine is described.

In two subjects receiving $12 \mathrm{~g}$. per day of the substance for seven days, plasma concentrations of 4 to $8 \mathrm{mg}$./100 ml. were maintained, and about $90 \%$ of the administered gentisate was recovered in the urine. When a single dose of $5 \mathrm{~g}$. was given to a healthy male the maximum plasma concentration $(15.5 \mathrm{mg} . / 100 \mathrm{ml}$.) appeared two hours after the dose, and $80 \%$ of the drug was recovered in the urine within eight hours.

\section{REFERENCES}

Camelin, A., Accoyer, P., Pellerat, J., Lafuma, J., and Coirault, R. (1949). Bull. Soc. méd. Hôp. Paris, 65, 826.

Consden, R., and Stanier, W. M. (1951). Biochem. J., 48, xiv.

Meyer, K., and Ragan, C. (1948). Science, 108, 281.

Smith, M. J. H. (1950). J. Pharm. Pharmacol., 2, 439. 